\title{
Meningococcal infections: reducing the case fatality rate by giving penicillin before admission to hospital
}

\author{
Jeffrie R Strang, Edwin J Pugh
}

\begin{abstract}
Objective-To determine whether parenteral penicillin given before admission to hospital reduces the case fatality rate in patients with meningococcal disease.

Design-Retrospective analysis of 46 consecutive patients admitted to hospital with meningococcal disease from January 1986 to March 1991.

Setting-District general hospital.

Main outcome measure-Hospital case fatality rate.

Results - None of the 13 patients given parenteral penicillin by the referring doctor before admission died, compared with eight deaths $(24 \%)$ in 33 patients admitted without such treatment.

Conclusion-Parenteral penicillin given before admission probably contributed to a reduction in the case fatality rate from meningococcal disease, and primary care physicians should be encouraged to give such treatment immediately on suspicion of the diagnosis before transferring the patient to hospital. Public health physicians are well placed to inform and alert general practitioners of the potential benefit of this action.
\end{abstract}

\section{Introduction}

Notifications of meningococcal meningitis to the Office of Population Censuses and Surveys increased in the 1980s. ${ }^{1}$ The Meningococcal Reference Laboratory has noted a similar rise in the number of isolates of Neisseria meningitidis between 1984 and $1990 .^{2}$ In England and Wales there were 1138 notifications of meningococcal meningitis and 277 notifications of septicaemia in 1990; there were 169 deaths from meningococcal disease, giving an overall case fatality ratio of 12\%. In 1990 in England and Wales 55\% of the deaths were in children under 5 years of age, with a further $23 \%$ of the deaths in patients aged 5-24 years. The death rate has hardly altered in the past 30 years. ${ }^{3}$

Despite increased understanding of the pathogenesis of these infections, the primary prevention of meningococcal disease remains elusive. Universal protection of the population is not yet possible as currently available vaccines provide only short term protection against group $\mathrm{A}$ and $\mathrm{C}$ strains of the organism, which accounted for only $32 \%$ of isolates in England and Wales in $1990 .^{2}$ There is no immediate prospect of an effective vaccine against group B meningococcus. ${ }^{4}$ Vaccine is currently used only for contacts of patients in whom a group $\mathrm{A}$ or $\mathrm{C}$ organism has been identified, and for the protection of travellers to areas of the world where meningococcal disease is endemic.

Professional and public concern about these infections heightened as a result of an outbreak in and around Stroud in the early 1980 s. $^{6}$ In response, the chief medical officer wrote to all general practitioners in 1988 to advise them of the epidemiology, early management, and prevention of spread of meningococcal infections. ${ }^{7}$ In particular, referring doctors were advised to consider giving parenteral benzylpenicillin before transferring the patient to hospital if the diagnosis was suspected, especially in the presence of a haemorrhagic rash. This guidance was reinforced in 1989 by the meningococcal infections working party of the Public Health Laboratory Service ${ }^{8}$ and by others, even though such a course of action might reduce diagnostic precision. It remains the cornerstone of advice to family doctors given by the National Meningitis Trust in their meningitis fact sheet. Concern has been expressed that early antibiotic treatment may do damage by rapidly killing bacteria, thereby releasing harmful endotoxin,$^{10}$ but there is little evidence to support delaying antibiotic treatment because of this possibility. ${ }^{11}$

Despite the consistent advice directed at referring doctors evidence is lacking for a reduced case fatality rate from meningococcal disease in those given penicillin before admission compared with those not so treated. We report the case fatality rates of patients admitted to one district general hospital in the Northern region and the impact on survival of treatment with parenteral penicillin before hospital admission.

\section{Methods}

All patients who were admitted to Darlington Memorial Hospital between 1 January 1986 and 31 March 1991 and who fulfilled the case definition were included in the study. They had had Neisseria meningitidis isolated from blood or cerebrospinal fluid, or both, or Gram negative diplococci had been seen in the cerebrospinal fluid, or clinical signs of meningitis or septicaemia had been accompanied by a haemorrhagic rash.

Patients were identified from the comprehensive register held in the microbiology department. A retrospective survey of the hospital records was carried out by one of us (JRS) after receiving written permission from the clinicians who were responsible for the patients under study. Data were collected on patient characteristics, provisional diagnosis of referring doctor, treatment before admission, hospital management including complications, microbiological findings, and outcome in terms of survival or death in hospital.

Statistical analysis was carried out by Fisher's exact test or the $\chi^{2}$ test.

\section{Results}

A total of 46 patients who fulfilled the case definition were admitted to Darlington Memorial Hospital during the study period. All cases in this study were sporadic, none being associated in time and place.
Kettlestring Lane, Clifton Moor, York YO3 4XF. 
Table I shows the number of cases and the population attack rates for the years 1986 to 1990 . The epidemic of 1990 persisted into 1991, when a further seven patients were admitted in the first quarter of the year. As meningococcal septicaemia did not become notifiable until October 1988, population attack rates for England and Wales combining meningococcal meningitis and septicaemia could not be calculated until that time. In 1989 and 1990, however, the national notification rates were $2 \cdot 7$ and $2 \cdot 8$ per 100000 , respectively; thus the local population attack rate in 1990 was four times the national notification rate.

A total of 24 patients $(52 \%)$ were under 5 years of age; $17(37 \%)$ were aged between 5 and 24 , with only five $(11 \%)$ aged 25 or over. Twenty five $(54 \%)$ patients were female. For the complete years 1986 to 1990, 27 patients $(69 \%)$ were admitted between October and March each year, with only $12(31 \%)$ admitted between April and September. Thirty five (76\%) patients had been seen by their own general practitioner or a colleague from the practice before admission; $\operatorname{six}(13 \%)$ were seen by a doctor from the local deputising service; five $(11 \%)$ were self referred to the accident and emergency department of the hospital.

TABLE I-Meningococcal infections, Darlington Memorial Hospital

\begin{tabular}{lcc}
\hline Near & No of cases & $\begin{array}{c}\text { Attack rate per } \\
100000 \text { population } \\
\text { per year }\end{array}$ \\
\hline 1986 & 8 & $6 \cdot 5$ \\
1987 & 3 & $2 \cdot 4$ \\
1988 & 9 & $7 \cdot 2$ \\
1989 & 5 & $4 \cdot 0$ \\
1990 & 14 & $11 \cdot 2$ \\
1991 & 7 & $\star$ \\
\hline
\end{tabular}

^Data available for January-March

TABLE II -Effect of alerting campaign on prescribing of penicillin before hospital admission and on outcome

\begin{tabular}{lccc}
\hline & $\begin{array}{c}\text { No of } \\
\text { patients }\end{array}$ & $\begin{array}{c}\text { No(\%) of patients given } \\
\text { parenteral penicillin } \\
\text { before hospital admission }\end{array}$ & $\begin{array}{c}\text { No(\%) } \\
\text { of } \\
\text { deaths }\end{array}$ \\
\hline $\begin{array}{l}\text { Before campaign } \\
\text { After campaign }\end{array}$ & 39 & $7(18)$ & $8(21)$ \\
\hline
\end{tabular}

\section{CASE FATALITY RATE}

The overall case fatality rate in the series was $17 \%$ (8/46). In all, $24 \%(8 / 33)$ of those who did not receive penicillin before admission died in hospital; there were no deaths in the 13 patients who had received parenteral penicillin before transfer to hospital ( $p=0 \cdot 106$, two tailed Fisher's exact test).

Considering only those cases in which the diagnosis had been suspected by the referring doctor, the death rate among the 13 patients given penicillin by injection before admission was zero, compared with a death rate of $22 \%(4 / 18)$ in those not given penicillin. Of the 33 patients admitted without being given parenteral penicillin, two had received oral penicillin, two had been given oral erythromycin, and one had been given cephalexin by mouth. All patients given oral antibiotics survived.

\section{PROVISIONAL DIAGNOSIS AND MANAGEMENT}

A diagnosis of meningitis or septicaemia had been suspected in $76 \%$ (31/41) of those seen by a doctor before transfer to hospital. When such a diagnosis had been suspected, however, only $42 \%$ (13/31) had been given parenteral penicillin by the primary care physician before admission.

\section{LOSS OF DIAGNOSTIC PRECISION}

Overall, an organism was detected in $72 \%(33 / 46)$ of cases. Parenteral penicillin given before samples for microbiological assessment were collected had a significant effect on the detection of the causative organism. Altogether, 15 patients were so treated: 13 patients had been given parenteral penicillin by the referring doctor and two had received treatment in the accident and emergency department before specimens were taken. Neisseria meningitidis or a Gram negative diplococcus was identified in $47 \%(7 / 15)$ of patients who had received such treatment before sample collection compared with $84 \%$ (26/31) of patients not so treated $\left(0.01>p>0.001, \chi^{2}\right.$ with Yates's correction, $\mathrm{df}=1)$.

\section{INFORMATION AND ALERTING CAMPAIGN}

In response to the increased incidence of cases in 1990, an information and alerting campaign directed at general practitioners and the local deputising service was launched by one of us (EJP) in January 1991. All family doctors were sent a pack containing two ampoules of benzylpenicillin, a copy of the Meningitis Trust's fact sheet, and a letter advising doctors to consider the diagnosis of meningococcal disease in appropriate circumstances and to give parenteral penicillin on suspicion, followed by rapidly transferring the patient to hospital. Table II shows the findings before and after the campaign. The short term benefit of this initiative both in terms of an increased rate of prescribing penicillin before admission and a reduced death rate is encouraging.

\section{Discussion}

The age, sex, and seasonal distribution of cases of meningococcal disease in Darlington during the study period were similar to those of notified cases in England and Wales as a whole. A high local population attack rate in 1990 persisted and indeed increased in 1991 , with 16 patients $(12 \cdot 8 / 100000$ population) being admitted to Darlington Memorial Hospital in that year. Seven of these were admitted in the first quarter of 1991 and were included in this analysis.

\section{IMPROVED OUTCOME}

The study was done to test the hypothesis that the early administration of parenteral penicillin contributes to an improved outcome in terms of survival in hospital. Despite the small numbers the observed differences, although not statistically significant in this study, are clinically important and merit interpretation. In an uncontrolled study such as this the possibility of confounding bias needs to be considered. Against a background of self limiting viral infections, which account for much of the daily work of family doctors, meningococcal disease requires a high degree $\tilde{N}$ of diagnostic acumen given that the average general $D$ practitioner is likely to see only three or four cases in a 30 year period. The patients who received penicillin $N$ before admission probably had the most obvious clinical presentation, a short history, and appeared gravely ill to the referring doctor. In fact, $31 \%(4 / 13)$ of those given penicillin before admission were clinically diagnosed as having disseminated intravascular $\stackrel{\mathbb{D}}{\rightarrow}$ coagulopathy, whereas only $9 \%(3 / 33)$ not so treated developed disseminated intravascular coagulopathy. Of those with this clinical diagnosis, $43 \%$ (3/7) died in hospital, but only $13 \%$ (5/39) without this complication died.

One interpretation of these data is that those patients given parenteral penicillin before admission were generally sicker and had a higher complication rate, yet all who received such treatment before transfer to hospital survived. An explanation for the association between penicillin given before admission and survival is that the suspicion of a diagnosis of meningococcal disease alters patient management, resulting in an improved outcome unrelated to the penicillin given by 
injection before admission. In our series, however, $13 \%(4 / 31)$ of patients referred by doctors died when the diagnosis had been suspected, with $20 \%(2 / 10)$ dying when the diagnosis had not been suspected.

Anaphylactic reaction to penicillin does exist, but many patients are incorrectly labelled as being allergic to penicillin. ${ }^{12}$ Although concern has been expressed about the potential harm from the rapid release of endotoxins, ${ }^{10}$ there is no evidence to suggest that such early antibiotic therapy results in a poorer outcome. Despite the small size of the study, clinically important observations are emerging. We hope that others will be encouraged to publish their findings so that evidence may accumulate to clarify the situation further. This study shows the soundness of the recommendation to give parenteral penicillin to all patients with meningococcal disease on suspicion of the diagnosis before transfer to hospital, despite the loss of diagnostic precision resulting from such a strategy.

\section{PUBLIC HEALTH PERSPECTIVE}

Much effort is expended in identifying and treating close contacts of each index case with rifampicin and, where appropriate, with vaccine to prevent secondary cases of meningococcal disease. Transmission between patients is rare, however, secondary cases accounting for only $0 \cdot 8 \%$ of all cases of meningococcal infection reported to the Communicable Disease Surveillance Centre from 1978 to $1987 . .^{8}$ Although it remains important to continue this work to prevent secondary cases, this study shows that a more proactive approach by this directorate of public health medicine by means of an information and alerting campaign directed at family doctors has had a positive effect on the high case fatality rate from this disease. The agenda of every public health physician who has responsibility for the surveillance and control of communicable disease should include mounting such a campaign and monitoring its effect on penicillin prescribing before admission and on mortality in hospital. In September 1991 public health physicians throughout the Northern region participated in alerting all general practitioners and deputising services about the importance of early antibiotic treatment for all suspected cases. Future surveillance of meningococcal disease throughout the region will include recording penicillin prescribing before admission and outcome in terms of survival or death in hospital.

We thank Dr F S Pagan, consultant microbiologist, and al physicians and paediatricians at the Memorial Hospital, Darlington, for allowing access to patient records. We also thank Dr Hilary Tillett of the Public Health Laboratory Service for her critical comments and advice in the statistical analysis. The information and alerting campaign in Darlington was supported by the Dawn Craggs Meningitis Appeal Fund.

1 Office of Population Censuses and Surveys. Infectious diseases, 1980-9 London: HMSO, 1980-91. (Series MB2, No 80/3-91/1.)

2 Jones DM, Kaczmarski EB. Meningococcal infections in England and Wales: report of the Meningococcal Disease Reference Laboratory for 1990 Communicable Disease Report 1991;1:R76-8.

3 Havens PL, Garland JS, Brook MM, Dewitz BA, Stremski ES, Troshynski TJ. Trends in mortality in children hospitalised with meningococcal infections, 1957 to 1987. Paediatr Infect Dis 7 1989:8:8-11.

4 Bjune G, Hoiby EA, Gronnesby JK, Arnesen O, Fredriksen JH, Halstensen , El

5 Department of Health. Immunisation against infectious disease. London: HMSO, 1990:166-72.

6 Cartwright KAV, Stuart JM, Noah ND. An outbreak of meningococcal disease in Gloucestershire. Lancet 1986;ii:558-61.

7 Department of Health and Social Security. Meningococcal infection: meningitis and septicaemia. London: $\mathrm{HMSO}, 1988$. (CMO(88) 2 .)

8 PHLS Meningococcal Infections Working Party. The epidemiology an control of meningococcal disease. Communicable Disease Report 1989;8:3-6. 9 Welsby PD, Golledge CI. Meningococcal meningitis. BMJ 1990;300:1150-1. 10 Hopkin DAB. Frapper fort ou frapper doucement: a Gram-negative dilemma. Lancet 1978;ii:1193-4.

11 Gedde-Dahl TW, Horby EA, Brandtzaeg P, Eskerud JR, Bovre K. Some arguments on early hospital treatment of suspected meningococcal diseas cases. NIPH Ann 1990;13:45-60.

12 Surtees SJ, Stockton MG, Gietzen TW. Allergy to penicillin: fable or fact? BMF 1991;302:1051-2.

\title{
Early treatment with parenteral penicillin in meningococcal disease
}

\author{
Keith Cartwright, Sheena Reilly, Diana White, James Stuart
}

Public Health Laboratory, Gloucestershire Royal Hospital, Gloucester GL1 3NN Keith Cartwright, director

Public Health Laboratory, Derriford Hospital, Plymouth PL6 8DH Sheena Reilly, consultant microbiologist

Public Health Laboratory, Royal United Hospital, Combe Park, Bath BA1 3NG

Diana White, director

\section{Gloucester Health}

Authority, Rikenel, Montpellier, Gloucester GL1 1LY

James Stuart, consultant in communicable disease control

Correspondence to: Dr Cartwright.

BMF 1992;305:143-7
Abstract

Objective-To measure the effect of parenteral antibiotics given before admission to hospital on mortality and on bacteriological investigations in meningococcal disease.

Design-Retrospective review of hospital notes and laboratory and public health medicine department records.

Setting-Three health districts in south west England.

Subjects-Patients with meningococcal disease in Gloucester district presenting between 1 January 1982 and 31 December $1991(n=190)$; patients with meningococcal disease in Plymouth $(n=118)$ and Bath $(n=73)$ districts presenting between 1 January 1988 and 31 December 1991 (total $=381$ ).

Main outcome measure-Number of deaths from meningococcal disease.

Results-Parenteral antibiotic given by general practitioners was associated with a substantial reduction in mortality (from $9 \%$ to $5 \%$; relative risk $0 \cdot 6,95 \%$ confidence interval 0.2 to $1 \cdot 5$ ); patients with a rash were more likely to be given parenteral antibiotics, and mortality was further reduced (from $12 \%$ to $5 \% ; 0.5,0.2$ to 1.4$)$. In a district where such treatment was regularly encouraged its use increased from $5 \%$ to $40 \%$ of cases over 10 years $(\mathbf{p}=0 \cdot 00001)$. Treatment with parenteral antibiotics before admission made isolation of meningococci from blood and cerebrospinal fluid less likely but did not affect nasopharyngeal cultures.

Conclusions-General practitioners should carry benzylpenicillin in their emergency bags at all times and should administer it promptly, preferably intravenously, whenever meningococcal disease is suspected, unless the patient has had an anaphylactic reaction to penicillin. Specimens for culture should include a nasopharyngeal swab.

\section{Introduction}

Data from the Office of Population Censuses and Surveys show that notifications of meningococcal disease in England and Wales rose in each year from 1984 to $1990 ; 460$ isolates from clinical cases were submitted to the Meningococcal Reference Laboratory in 1984, compared with 1500 in 1990 . Nearly all cases were due to strains of serogroups B and C.' Although serogroup A plus $C$ vaccines are available they confer only short term protection, are not adequately immunogenic in children, and are therefore not suitable for a universal immunisation programme. ${ }^{2}$ Serogroup $B$ vaccines are not sufficiently developed for widespread use at present. ${ }^{34}$ 